\title{
Atenas, entre el amor y la anarquía: la democratización de los placeres y las contingencias de la política popular
}

Athens, between love and anarchy: democratization of pleasures and the contingencies of popular politics

\author{
Por: Julián Gallego* \\ PEFSCEA/Universidad de Buenos Aires-CONICET, Argentina \\ Email: julianalejandrogallego@gmail.com \\ ORCID: 0000-0002-3394-357X \\ Fecha de recepción: 25/02/2019 \\ Fecha de aprobación: 30/04/2019 \\ Doi: $10.30972 /$ nvt.0143707
}

Resumen: En República, Platón describe a la democracia como un régimen anárquico, abigarrado y placentero (hedeîa), porque reparte la misma igualdad para todos. Esto genera un exceso de libertad que conduce a que se pueda hacer lo que se desee ( $t i$ bouletai), que Platón al igual que Aristóteles en Política consideran uno de los males principales de la democracia, y que este último explica a partir del hecho de que para la multitud es placentero (hedion) vivir en desorden y no con moderación. Si esta última primara el placer y el deseo quedarían restringidos o incluso anulados. De esta manera, la política democrática se caracteriza por el placer que produce, en tanto que habilita la posibilidad de que se materialice en y por el deseo de cada quien. Esto es lo que se ha planteado, desde diferentes perspectivas, como una erótica de la política (e.g. Victoria Wohl, Love among the Ruins: The Erotics of Democracy in Classical Athens; Andrew Scholtz, Concordia Discors: Eros and Dialogue in Classical Athenian Literature), una de cuyas dimensiones más evidentes es la relación amorosa, símbolo paradigmático de esta intersección entre placer y deseo, excepto que se los controle o se los suprima. Estas alternativas son las que Tucídides encarna en el Discurso Fúnebre que atribuye a Pericles, cuya propuesta de que los atenienses sean amantes (erastas) de la polis remite la cuestión a una entidad abstracta sin que haya placer en ese

\footnotetext{
* Doctor en Historia por la Universidad de Buenos Aires (Argentina). Investigador principal del Consejo Nacional de Investigaciones Científicas y Técnicas (CONICET, Argentina). Docente de Historia Antigua II, Facultad de Filosofía y Letras, Universidad de Buenos Aires (Argentina).
} 
recurso amoroso. Aristófanes en Caballeros repone el principio del placer-deseo y lo inscribe en los intercambios entre los propios atenienses a partir de la figura del erastês toû démou, jugando con los roles activo y pasivo de las relaciones pederastas y transformando en prostitución la metafórica relación amorosa entre el demagogo y el pueblo. Sobre esta construcción se monta Platón en Gorgias y en Alcibíades I, donde acuña el término demerastês. El recorrido propuesto busca demostrar que todas estas expresiones tratan de des-investir al dêmos de su poder por su falta de cualificación, su mescolanza, su desorden, incapacitado como está de practicar el verdadero amor, en definitiva, por la anarquía que la democracia representa.

Palabras clave: Atenas - Dêmos - Demagogo - Amor - Anarquía

Abstract: In Republic, Plato identifies democracy as a political regime that is anarchic, manifold and pleasant (hēdeia), because it distributes the same equality for everyone. This generates an excess of freedom that provokes each one to do what he wishes ( $t i$ bouletai), which Plato considers one of the main evils of democracy, and Aristotle in Politics explains it from the fact that is pleasant (hẽdion) for the multitude to live in disorder and not in moderation; but if the latter prevails, so pleasure and desire would be restricted, or even canceled. Thus, democratic politics is characterized by the pleasure it produces, while enabling the possibility to materialize in and by the desire of each one. From different perspectives, this is what has been studied as an erotics of politics (e.g. Victoria Wohl, Love among the Ruins: The Erotics of Democracy in Classical Athens; Andrew Scholtz, Concordia Discors: Eros and Dialogue in Classical Athenian Literature), one of whose obvious dimensions is the loving relationship, a paradigmatic symbol of the intersection between pleasure and desire, unless these are controlled or suppressed. These are the alternatives that Thucydides enables in the Funeral Oration attributed to Pericles by him, whose proposal the Athenians to be lovers (erastas) of the polis refers the question to an abstract entity without there being any pleasure in that loving resource. In Knights, Aristophanes reinstates the pleasure-desire principle and inscribes it in the exchanges between the Athenians themselves based on the figure of the erastēs tou dèmou, playing with the active and passive roles in pederastic 
Atenas, entre el amor y la anarquía: la democratización de los placeres y las contingencias de la política popular

relationships and turning into prostitution the metaphorical loving relationship between the demagogue and the people. Plato is mounted on this understanding in Gorgias and in the first Alcibiades, where the term dèmerastēs is coined. The intent is to demonstrate that all these expressions seek to dis-invest the people of their power because of their lack of qualification, their mess, their disorder, incapacitated as they are to practice true love, in short, by the anarchy that democracy depicts.

Keywords: Athens - Dēmos - Demagogue - Love - Anarchy

\section{Cómo citar este artículo:}

APA: Gallego, L. R. (2019). Atenas, entre el amor y la anarquía: la democratización de los placeres y las contingencias de la política popular. Nuevo Itinerario, 14 (1), 58-85. Recuperado de: (agregar dirección web)

\section{Introducción}

El título propuesto en una versión preliminar de este trabajo había adoptado la siguiente formulación: "Esa banda inconsolable: el dêmos ateniense, sus amantes y la democratización del goce" ${ }^{1}$. Pero esto contenía varios lugares implícitos que se hacía necesario explicitar, aun cuando para algunos las referencias fueran evidentes. "Esa banda inconsolable" son las palabras con las que empieza la canción "Buenas noticias" de Patricio Rey y sus redonditos de ricota, un mítico grupo de rocanrol argentino, cuyas imágenes en cuanto a quiénes son los integrantes de esa banda bien podrían ajustarse a ciertas características que se asignan al dêmos en algunas "descripciones". Por otra parte, las últimas cuatro palabras refieren a la caracterización que hacía Daniel Santoro (2014), un pintor argentino, cuando afirmaba en una entrevista, apelando a una jerga lacaniana: "El problema del peronismo no es la lucha de clases sino la democratización

\footnotetext{
${ }^{1}$ Este artículo es una versión enteramente revisada de un texto que, en su etapa preparatoria, tuve la ocasión de exponer en las IX Jornadas sobre el Mundo Clásico: "Formas del amor en el Mundo Antiguo", de la Facultad de Filosofía, Ciencias de la Educación y Humanidades, Universidad de Morón, gracias a la amable aceptación de la Dra. María Cecilia Colombani, en las II Jornadas de Filosofía Antigua, Sección de Estudios de Filosofía Antigua, Centro de Estudios Filosóficos "Eugenio Pucciarelli", Academia Nacional de Ciencias de Buenos Aires, gracias a la gentil invitación de la Dra. Claudia Mársico, y en la Jornada de Debate "Toposofía", del Departamento de Historia I, Facultad de Geografía e Historia, Universidad de Santiago de Compostela, gracias al cordial convite de los Dres. Pedro López Barja de Quiroga y Marco García Quintela. Agradezco sus observaciones y sugerencias a quienes participaron de estos eventos. El texto se ha visto beneficiado también de la lectura atenta y los agudos comentarios de Milena Lozano Nembrot, a quien expreso aquí mi gratitud. Por supuesto, todo error remanente en este trabajo o falta de claridad son de mi exclusiva responsabilidad.
} 
del goce"; y, aunque no ilustren exactamente esta idea, los cuadros que ha producido perfilan en cierta medida algunas de las peculiaridades de su singular obra pictórica.

Buscando una formulación menos localista de mi pensamiento necesariamente situado, había llegado a una denominación que intentaba hacer estricta justicia a los dos planos de reflexión que aquí se cruzan, la historiografía y la filosofía: "Lugares del saber-hacer político en Atenas: los placeres en el amor del pueblo y en la anarquía del gobierno de cualquiera". Pero no conforme aún con esta versión de mis ideas, antes de llegar al título finalmente adoptado, de un modo tal vez más cosmopolita, a partir de la abstracción que todo título intenta siempre destacar como horizonte problemático, una tercera explicitación del problema proponía: “Amor y anarquía: los 'fundamentos' contingentes de la democracia ateniense", apelando al título D'amore e d'anarchia de la bella película de Lina Wertmüller (1973), como debería manifestarse con claridad².

Como las líneas previas y el rótulo finalmente adoptado lo anticipan, en este artículo se examinan tres tópicos articulados entre sí: la política popular, o, lo que es lo mismo, la potencia democratizadora desplegada por la actuación del dêmos ateniense, y los efectos que este despliegue produce en términos subjetivos (asociados con los placeres, los deseos, el amor) e institucionales (asociados con las contingencias de la autonormativización, la anarquía). En este marco, resulta fundamental el relevamiento de las emociones entendidas como estructuradoras de las configuraciones políticas, puesto que proveen un componente cognitivo esencial a partir de juicios de valor, es decir, implican la apreciación o la evaluación de un "objeto externo", cimentado en creencias y percepciones que se hallan necesariamente en relación con la comunidad

\footnotetext{
${ }^{2}$ Si se dedican los primeros párrafos de esta introducción a los avatares de un título durante el proceso de producción y redacción es porque ponen de relieve un problema clave, cual es el de la traducibilidad (o intraducibilidad), podría decirse siguiendo a Barbara Cassin (2016, pp. 27-86), es decir, cómo se hacen inteligibles (o ininteligibles) las propias ideas con vistas a una interpretación que se quiere comunicar, sin por ello deshacerse en la universalidad. Este problema no es banal y, como ya se verá, afecta tanto al propio argumento que aquí se busca articular discursivamente cuanto a la traducción de las fuentes. Se puede observar, entonces, que los lugares desde los que se plantea cualquier interrogación son, por su propia idiosincrasia, lugares situados, valga la redundancia, dado que las preguntas que se formulan al pasado no están al margen de los lugares del saber, por así denominarlos, desde los cuales se piensa, se hace y se practica la Historia Antigua, en el caso específico que atañe a este texto. Dicho de otra forma, interrogarse desde Argentina, o más precisamente desde Buenos Aires, sobre el despliegue de la política en la Atenas democrática incluye una nota idiosincrática que, por consiguiente, se halla situada y no es necesariamente semejante a plantearse esas mismas preguntas en otros contextos.
} 
Atenas, entre el amor y la anarquía: la democratización de los placeres y las contingencias de la política popular

de pertenencia ${ }^{3}$. Estas pasiones son, pues, hechos sociales más que manifestaciones meramente individuales y, por ende, ayudan a pensar la dinámica democratizadora. Así concebidas, las emociones implican una negociación sobre el sentido de los hechos frente a los cuales responden y, en tanto que práctica ideológica, permiten vislumbrar patrones morales, jurídicos, religiosos u otros que conciernen a la comunidad.

El papel de las pasiones en las prácticas políticas se percibe a partir de diversos indicios, como sucede con la cólera (orgê) como detonante de la guerra civil (stasis). En relación con la política democrática ateniense, el coraje (tolma, thymos) aparece como un atributo ligado a la capacidad de pensar y decidir y la responsabilidad de actuar en consecuencia: el conocimiento es un componente del coraje que está acompañado de una predisposición a correr riesgos como un rasgo de identidad cultural del dêmos; su contrapartida es el miedo (phobos), que cuando se manifiesta políticamente inhibe la capacidad de pensar y decidir y genera desconfianza y desconocimiento. La presencia del coraje y el miedo en el proceso democrático habilita así la dimensión emocional en la praxis política, cuestión generalmente relegada en las explicaciones racionalistas de la misma. Las pasiones políticas apuntan a replantear este problema haciendo hincapié en que las configuraciones políticas no se explican con arreglo a visiones puramente racionales, sino que se debe considerar asimismo los aspectos emocionales ${ }^{4}$.

En este contexto general, se puede afirmar también que hay una erótica de las pasiones políticas, según el modo en que los ciudadanos se unían gracias a lazos de afecto mutuo (amistad cívica, amor, sexualidad) que permitían articular lo público con lo privado, el compromiso político con el amor erótico. En Atenas se desarrolló un ideal del ciudadano perfecto como un amante noble y varonil que incitaba a los atenienses a convertirse en amantes de la ciudad y a los políticos en amantes del pueblo, poniendo así de relieve que la erótica formaba parte de la política. Esto implica otra dimensión cognitiva que permitía obtener un conocimiento más acabado de cómo, consciente o

\footnotetext{
${ }^{3}$ Para diversas teorías de las emociones, Calhoun \& Solomon (ed. 1984). Sobre el elemento cognitivo de las emociones, Nussbaum (2001); (2004). Cf. Konstan \& Rutter (eds. 2003); Konstan (2004); (2006); (2007). Para la relación entre política y emociones en la democracia ateniense, con particular atención puesta en la comedia aristofánica, ver los trabajos reunidos en Gallego \& Fernández (eds. 2019).

${ }^{4}$ Sobre la relación entre orgê y stasis en Tucídides, Loraux (2008b, pp. 105-133). Sobre el rol de thymos en la política, Koziak (2000). Ver la valiosa serie de trabajos sobre democracia ateniense y coraje de Balot (2001); (2004a); (2004b); (2004c); (2007); (2008); (2009); (2010); (2014). Cf. Gallego (2015); (2016).
} 
inconscientemente, los deseos tenían su lugar en la política democrática ateniense.

\section{La erótica esterilizada del Discurso Fúnebre de Pericles}

Así pues, vamos a plantear el problema delimitado en el terreno de una erótica de la política, que ha sido examinado de modo general por Paul Ludwig (2002, pp. 1018) y de manera más específica por Victoria Wohl (2002, pp. 1-12) y Andrew Scholtz (2007, pp. 9-19) ${ }^{5}$. La articulación entre la política y la erótica tiene antecedentes en Tucídides, en particular en un pasaje de la oración fúnebre de Pericles, y en la posible parodia de Aristófanes en Caballeros a la expresión que el líder pudo haber utilizado efectivamente. La conexión entre ambos textos ha sido agudamente examinada por Wohl (2002, pp. 30-123) y Scholtz (2007, pp. 21-69) ${ }^{6}$, por lo que, apoyándome en sus demostraciones, solo me limitaré aquí a señalar algunos elementos respecto de estos discursos en función del eje de análisis que me interesa. Según las palabras dichas por Pericles en un pasaje del discurso fúnebre que le atribuye Tucídides (2.43.1): "Debéis contemplar, en cambio, la potencia de la ciudad (ten tês poleôs dynamin) en la realidad de cada día y convertiros en amantes de ella (erastas... autês)"”. Cabe señalar aquí un obstáculo de traducibilidad, porque autês puede remitir a dynamin así como a poleôs, que hemos vertido en femenino, "la potencia de la ciudad", para conservar en español la misma disposición del texto griego. En su versión, Guzmán Guerra (1989) relaciona autês con dynamin, por lo que, antes que a la ciudad en sí misma, el enamoramiento se dirige al poder obtenido por ella. Torres Esbarranch (1990), cuya traducción utilizo con leves cambios para destacar el punto, indica que se trata del amor a la ciudad y no a su poder (ad loc., n. 307), y remite a Acarnienses (143) y Caballeros (732, 1340-1344) de Aristófanes y Alcibíades (132a) de Platón, textos en los que, sin embargo, el término erastés no aparece articulado con la pólis sino, sobre todo, con el dêmos. Optando por la lectura que propone Torres Esbarranch, cabe indicar que la de Guzmán Guerra no se aparta de los cánones de interpretación del pasaje tucidideo, puesto que aun si autês

\footnotetext{
${ }^{5}$ Cf. asimismo el libro básico de Calame (2002, pp. 95-131), quien sin embargo no otorga relevancia a las metáforas eróticas usadas en relación con la política que aquí se analizan.

${ }^{6}$ Cf. sobre Tucídides, Ludwig (2002, pp. 153-169), y sobre Aristófanes, Rothwell Jr. (1990, pp. 26-43).

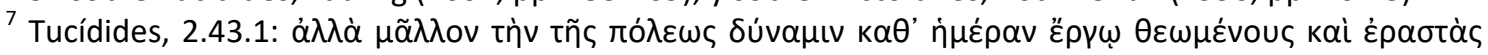
үıүvouḱvouৎ aủtñৎ (Jones \& Powell, 1942).
} 
Atenas, entre el amor y la anarquía: la democratización de los placeres y las contingencias de la política popular

se considera en relación con dynamin, el amor que Pericles propone poner de relieve cada día se dirige asimismo a la ciudad por medio de la potencia como un atributo que le es propio, plenamente suyo, colocado en el mismo plano de abstracción. José Solana Dueso (1994, pp. xlvi-xlvii) interpreta que el enunciado pericleo era ya una consigna prestigiosa que formaba parte del ideario concreto de los demócratas atenienses, y que se puede asociar a otras construcciones que también evocan el amor a la ciudad (philopolis) $^{8}$. Ahora bien, en la medida en que el amor se encamina hacia una entidad abstracta, se trata entonces de una versión esterilizada de la erótica política, sin que haya placer ni deseo en este recurso al amor: la oración fúnebre de Pericles parece apelar a la retórica persuasiva, pero sin ninguna pretensión hedonista, buscando solo los fines más elevados, lo mejor para la ciudad. En este punto, siguiendo el análisis de Sara Monoson (1994), este ejercicio de autocontrol y masculinidad se podría llegar a asimilar a una situación de autoerotismo, puesto que la pólis, que solo se concibe aquí como la propia comunidad de varones ciudadanos, aparece colocada en la posición del erómenos con respecto al cual los ciudadanos deben convertirse en sus erastai: de un lado y del otro, los ciudadanos, que siendo amantes de la pólis se aman a sí mismos.

\section{La erótica pornográfica de Caballeros de Aristófanes}

A esta imagen elevada del líder político hablando ante el pueblo se contrapone la construcción taxativa del propio Tucídides (2.65) con respecto a Cleón y los demás demagogos posteriores a Pericles, siempre más preocupados en complacer al pueblo en la asamblea y los tribunales, para obtener sus favores y acumular poder mediante el uso retórico del lenguaje, que en buscar y llevar a cabo lo mejor para Atenas. Pero en Caballeros, Aristófanes fusiona a Pericles con Cleón y repone así el principio del placerdeseo inscribiéndolo en los intercambios entre los propios atenienses. Es significativo al respecto la discusión entre Paflagonio y Morcillero por ganarse el amor de Demo ${ }^{9}$ :

D.: ... Paflagonio, ¿quién te agravia? | P.: Por ti me están golpeando / ése de

\footnotetext{
${ }^{8}$ Cf. Esquilo, Siete contra Tebas, 176; Píndaro, Olímpicas, 4.16; Eurípides, Reso, 158; Tucídides, 2.60.5; 6.92 .2 y 4; Aristófanes, Lisístrata, 546; Pluto, 726, 900; Isócrates, 2.15; Jenofonte, Hierón, 5.3; Platón Apología, 24b; República, 470d, 503e; Plutarco, Moralia, 540c.

${ }^{9}$ Respecto de los usos del amor por parte de Aristófanes, ver de manera general Robson (2013).
} 
ahí y los jovenzuelos. | D.: ¿Por qué? / P.: Porque te quiero, Demo, amante tuyo soy (philô s'ô Dêm' erastes t' eimi sos). / D. Y tú en realidad ¿quién eres? | M.: El amante rival (anterastes) de ése, / que te lleva amando mucho tiempo (erôn palai sou) y quiere servirte bien, / como muchos otros nobles y honrados (kalous te $k^{\prime}$ agathous), / pero que por su culpa no podemos, ya que / eres igual a los muchachos cortejados (toîs paisi toîs eromemois): / no aceptas a los nobles y honrados, / y a vendedores de lámparas y cordeleros, / a zapateros y curtidores te ofreces (Caballeros, 730-740) ${ }^{10}$.

Aludiendo a este vínculo, que el triunfo de Morcillero en la contienda dialéctica con Paflagonio vendría a desterrar de la política ateniense -en la medida en que aquél solo en apariencia es igual o peor que éste, y termina siendo la punta de lanza del proyecto de los caballeros kaloi k'agathoi-, Morcillero vuelve a poner de manifiesto en el final de Caballeros (1340-1342) cuál es el modo de relación erótica entre el pueblo y los demagogos, que su victoria ha venido a desterrar de la democracia: "Siempre que alguien decía en la asamblea: 'Demo, amante tuyo soy, te quiero (Dêm' erastês eimi sos philô te) y soy el único que cuida de ti y vela por tus intereses'"11; repitiendo en otro orden las mismas palabras utilizadas en el pasaje anteriormente citado. Según Scholtz (2004; 2007, pp. 43-69), Aristófanes pone en escena el topos de la demophilia como un cortejo pederasta que destaca las tensiones entre el ideal de la benevolencia (eunoia) y la denigrada imagen de la adulación (kolakeia) y, al mismo tiempo, borra las fronteras entre ambas produciendo su interpenetración, con el dêmos como un pornos que sin embargo no deja de perseguir sus propios fines. Así, el elevado amante de la ciudad de la oración fúnebre periclea se convierte en el erastes toû demou, haciendo

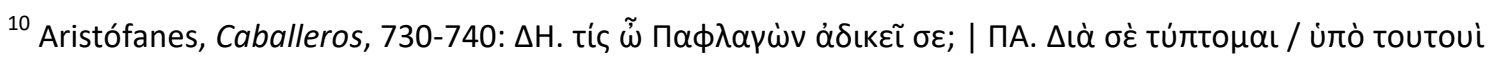

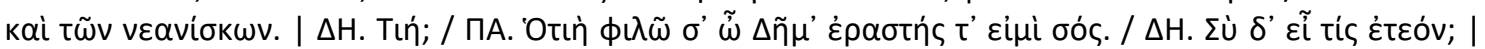

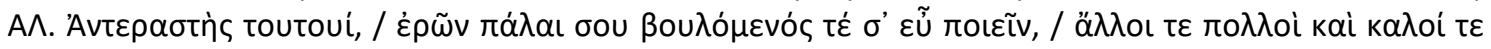

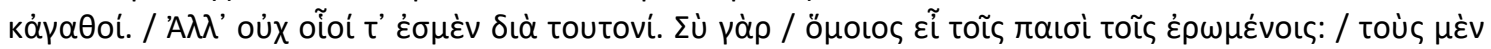

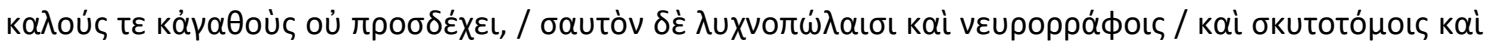

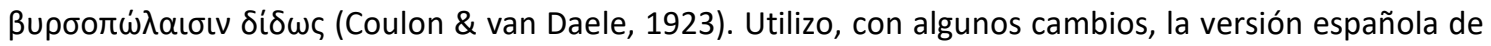
Gil Fernández (1995).

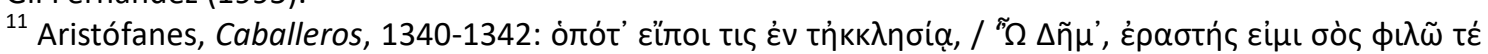

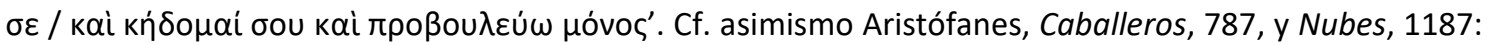
philddemos; Acarnienses, 142-143: philathenaois... hymôn t' erastes; Montepaone (1992, pp. 208-209 y n. 27-28).
} 
Atenas, entre el amor y la anarquía: la democratización de los placeres y las contingencias de la política popular

jugar en escena los roles activo y pasivo de las relaciones pederastas y transformando al mismo tiempo en prostitución la metafórica relación amorosa entre el demagogo y el pueblo. Haciendo mías las palabras de esta extensa cita de Wohl (2002, p. 75):

En Caballeros de Aristófanes, la relación paródica de Cleón con Pericles se desarrolla en gran parte en torno a la metáfora del eros. Allí Cleón se hace eco directamente de la dicción erótica de Pericles en el Epitafio, describiéndose a sí mismo como el erastés de Demo. El noble 'amor a la pólis' de Pericles se convierte, en la representación degradada de Cleón, en prostitución política. Ya no es Demo el orgulloso amante de una hermosa ciudad y sus gloriosos muertos; por el contrario, se ha convertido en el erómenos, y en uno glotón y decrépito, además. Prometiéndose al político que ofrece los mejores regalos este eromenos poco atractivo también se convierte en un pornos, un puto. El pueblo son los 'muchos por un óbolo' (Caballeros 945), que se venden al mejor postor y son muy baratos. Los líderes del pueblo no son mejores. Mientras que Pericles era él mismo la encarnación suprema de los ideales que propugnaba, Cleón sobrepasa a Demo en desvergüenza: él también está en venta, gratificando a Demo a cambio del favor político. En su adaptación del idioma erótico de Pericles, Cleón convierte el amor en prostitución y el noble erastés en un puto común.

Así, el funcionamiento de la política democrática se representa a partir de una erótica que, en el límite, da lugar incluso a una pornografía. El análisis de Milena Lozano Nembrot (2018b) sobre los erotikoi logoi de Lisias, a partir de su Discurso de defensa contra Simón (III) y de la alocución que Platón le asigna en Fedro ${ }^{12}$, permite poner de manifiesto de manera complementaria un conjunto de aspectos que se conectan con el problema del erastês toû demou, puesto que si bien el discurso de Lisias remite a relaciones eróticas entre individuos, sin embargo, éstas se ventilan en tribunales que eran una suerte de asambleas de ciudadanos en pequeña escala. La

\footnotetext{
${ }^{12}$ Cf. también Lozano Nembrot (2016); (2018a).
} 
disputa por el amor del muchacho de Platea entre los dos ciudadanos puede parangonarse, salvando las distancias, con la disputa entre Paflagonio y Morcillero por el amor de Demo en Caballeros de Aristófanes, aunque en este último caso el viejo que actúa fuera de lugar es el propio Demo, a diferencia del cliente de Lisias: es decir, el viejo Demo es el erómenos y no uno de los erastai. El hecho de que, junto con las representaciones de la poética cómica en el lugar del saber-hacer teatral, el discurso oratorio forense sea también parte de un lenguaje común de los atenienses pone de relieve que en el espacio del saber-hacer de los tribunales había unas condiciones de decodificación de los discursos allí proferidos, que en el caso particular que aquí nos interesa se liga a una concepción de la erótica como parte de un marco cultural de la pólis en su conjunto. Consecuentemente, cuando Aristófanes echaba mano de estos mismos elementos en Caballeros estaba apelando a ese sustrato cultural común que daba sentido a la parodia entre el viejo Demo como erómenos y los demagogos como erastai, utilizando las inversiones paródicas inherentes a la comedia. En este contexto, cada demagogo trata de sustraer a Demo del amor del otro, como el amado que solo debería ser la compañía de uno de los demagogos, para transformarse en su amante en exclusividad. Milena Lozano Nembrot (2018b, pp. 64-65) también Ilama la atención sobre otro punto de gran relevancia para las concepciones de la política y la erótica:

Todo lo que generaba consecuencias indeseables era llamado con el nombre de nosos 'enfermedad' o symphora 'desgracia, evento desafortunado', palabras que también denotan una fuente externa al agente. Estas circunstancias, prácticamente inevitables, hacen que el que está dominado por ellas no pueda pensar racionalmente y decidir por sí mismo, sino que actúe bajo los efectos de la locura.

Acotemos a la pasada que, si bien nosos no forma parte del vocabulario de la comedia aristofánica, sí se utiliza el término symphoraîs dos veces, que tendría en ambos casos el raro significado de "eventos felices" (Caballeros, 406, 655) ${ }^{13}$, pero de

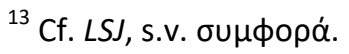


Atenas, entre el amor y la anarquía: la democratización de los placeres y las contingencias de la política popular

los que cabe sospechar, teniendo en cuenta las transgresiones cómicas, la soterrada búsqueda de una inversión de su sentido. Este interesante cruce entre enfermedad y erôs nos acerca a una de las formas de caracterizar la stasis dentro de la polis, que Nicole Loraux (2008a; 2008b) ha estudiado agudamente: la stasis es connatural a la política de la pólis, pero el pensamiento griego hace de la guerra civil una enfermedad que altera la normalidad de la ciudad sana, unida y $\sin \operatorname{conflictos}^{14}$. Así, eros y stasis parecerían coincidir en el punto en que se conciben como alteraciones de la normal racionalidad del logos, cuando éste se cruza con el campo de la política (democrática).

\section{"Es un cualquiera": la exousia de la democracia, o la anarquía de los placeres}

Exploremos ahora otros argumentos en los que los placeres del amor del y por el pueblo se entrecruzan con el problema de la anarquía. Efectivamente, en República (558c), Platón caracteriza a la democracia no solo como anárquica y abigarrada sino también como un régimen político placentero (hedeîa politeia) porque distribuye la misma igualdad (isoteta) para todos indistintamente, sean iguales (isois) o desiguales (anisois). Según el filósofo ha argumentado previamente (557b), el problema radica en que esto entraña tal exceso de libertad para la ciudad (kai eleutherias he polis mestê kai parrhesias) que la conduce a una situación de total libertinaje, de abuso de poder, de manera que en ella cualquiera puede hacer lo que desee (kai exousia en autêi poieîn hoti ti bouletai). En efecto, según el sentido del pasaje, esta exousia implica un abuso de poder, un evidente exceso, por el cual "Ilaman a la desmesura cultura, a la anarquía libertad, a la prodigalidad magnificencia y a la impudicia virilidad" (560e$561 a)^{15}$. Así, la igualdad democrática conduce finalmente a la subversión de todas las jerarquías, puesto que cualquiera hace allí lo que le plazca: los hijos respecto de los padres, los metecos y extranjeros respecto de los ciudadanos, los discípulos respecto de los maestros, los jóvenes respecto de los adultos e, incluso, los esclavos respecto de los amos, las mujeres respecto de los varones y, en el colmo, los animales respecto de los hombres a quienes deberían servirles, ya que tienen total libertad para andar por

\footnotetext{
${ }^{14}$ Cf. Gallego (2011, pp. 337-339).

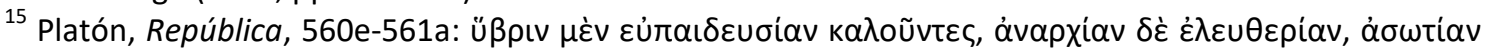

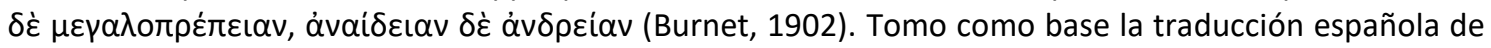
Eggers Lan (1986), con modificaciones cuando lo he creído pertinente, en función de la interpretación.
} 
donde quieran y dar empellones a los hombres (562e-563e), como un símbolo tal vez de que todos los inferiores que ejercen el poder en una democracia estarían sumidos en la inmediatez de la animalidad. Siguiendo a Martin Breaugh (2007, p. 11), se podría decir que la razón implícita en este argumento sería, en última instancia, remarcar el estatus infrapolítico de quienes deberían estar privados del uso de la palabra pública (logos) y, de esta manera, quedar reducidos solo a la más simple expresión animal del placer y el dolor (phonê) $)^{16}$. Aristóteles (Política, 1253a 7-18) traza una distinción entre estos términos como principio de diferenciación entre el hombre (anthropos) y otros animales gregarios: la emisión de sonidos (phonê) para expresar placer o dolor es condición necesaria pero no suficiente para la humanidad; se debe poder comunicar articulando un sentido codificado mediante el discurso (logos) que permite decir lo que es propiamente humano: lo útil y lo perjudicial, lo justo y lo injusto, el bien y el mal. Esto no es posible de modo aislado sino como parte de una comunidad, y bien mirado define los parámetros que delimitan el ser hombre bajo la figura del ciudadano de una pólis (zôon politikon). En este marco, la conclusión platónica es muy elocuente en cuanto a la elusión de las obligatorias normas que genera la democracia y, por eso, aparenta estar más cerca de la animalidad de la phonê que de la humanidad del logos:

¿Y no te percatas que, como resultado de la acumulación de todas estas cosas, el alma de los ciudadanos se torna tan débil (hapalen) que, si alguien le proporciona siquiera una pizca de esclavitud (douleias tis), se irrita y no lo soporta? Pues bien sabes que de alguna manera terminan por no prestar atención ni siquiera a las leyes orales o escritas, para que de ninguna forma tengan amo alguno (medeis autoîs êi despotes) (República, 563d-e) ${ }^{17}$.

Esta perspectiva sobre la democracia no es exclusiva del Platón, puesto que Isócrates se pronuncia en términos muy similares tanto en Areopagítico como en

\footnotetext{
${ }^{16}$ Cf. Agamben (2000, pp. 136-137); Gallego (2014).

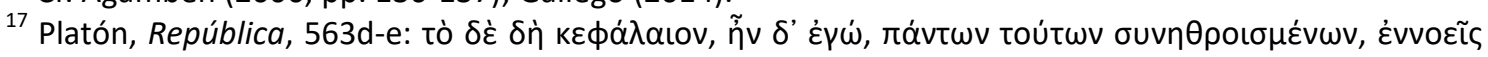

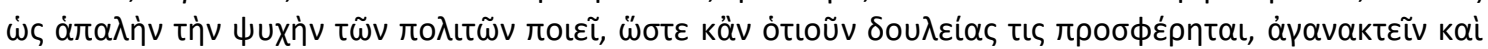

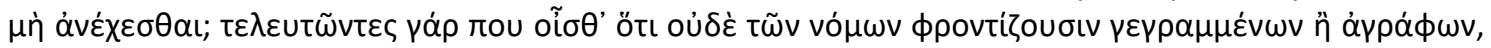

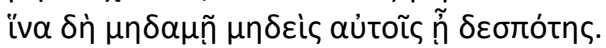


Atenas, entre el amor y la anarquía: la democratización de los placeres y las contingencias de la política popular

Panatenaico, al cotejar en ambos discursos la constitución ancestral, esto es, la democracia instaurada por Solón y restablecida por Clístenes, con la situación que estaría vigente en la Atenas de su tiempo. En efecto, en el primero de los textos (7.2022) el problema que explícitamente se destaca es la existencia de dos igualdades, una que asigna lo mismo para todos (tês $t^{\prime}$ auton hapasin aponemouses), que es la que Platón ponía de relieve, y otra que da a cada uno según su mérito (kata ten axian); mientras que esta última es la que se había puesto en obra en la constitución ancestral, en cambio, en la situación criticada por Isócrates la vigencia de la primera llevaba a que se considerase que "era democracia el libertinaje, libertad la ilegalidad, igualdad política la libertad de palabra y felicidad el abuso de poder hacer todo esto" ${ }^{18}$. En el segundo testimonio (12.130-131), prácticamente en el final de su vida, el orador insiste con su visión sobre las virtudes de la constitución ancestral, que se remonta a Cécrope, Erictonio y sus descendientes hasta Teseo, quien entrega el gobierno a las generaciones más recientes: una democracia que no gobierna al azar ni cree que "el libertinaje es libertad y el abuso de poder hacer cualquiera lo que desee felicidad" 19 .

En Areopagítico (12.130), Isócrates parece distanciarse de Platón al describir la constitución ancestral "no solo como la más imparcial y más justa sino también como la más conveniente para todos y la más placentera (hedistes) para los que la usan"20. Esta diferencia de criterios en cuanto al papel del placer en relación con la constitución tal vez resulte algo anecdótico, aunque imposible de ignorar en el contexto de nuestro argumento. El problema quizás no radique solamente en el carácter placentero sino en su conjunción con los excesos y los abusos inherentes al tipo de democracia en la que impera la misma igualdad para todos y, por ello, se puede hacer lo que se desee, como ya veremos. Más allá de todo esto, lo que Isócrates y Platón ponen de manifiesto es el hecho de que existe una dimensión de la democracia que se articula con el placer.

Aristóteles no es ajeno a esta problemática (Política, 1310a 25-36). La dificultad

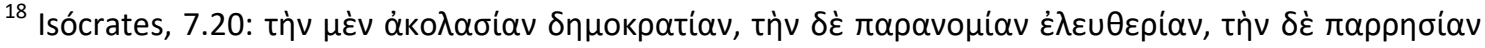

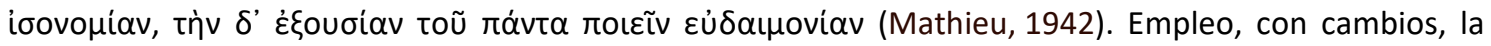
traducción española de Guzmán Hermida (1980).

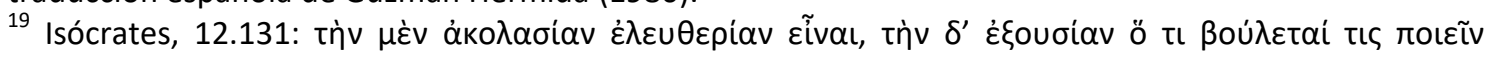

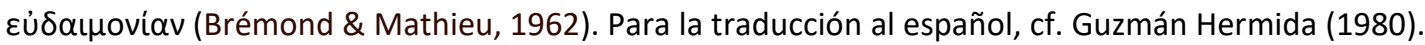

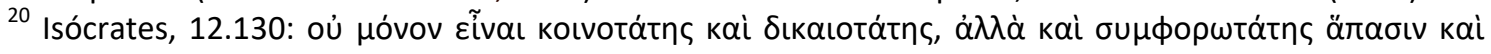

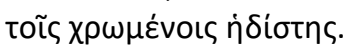


de las democracias más extremas estriba en que definen mal la libertad, porque al ser la multitud soberana (to pleîn eînai kyrion) se equiparan justicia con igualdad y ésta con la opinión de la multitud (doxe tôi plethei); así, la libertad y la igualdad se identifican con hacer lo que cualquiera desee (eleutheron de kai ison to ho ti an bouletai tis poieîn). "De modo que, colige Aristóteles, en tales democracias vive cada uno como esee y va a donde quiera (zê... hekastos hos bouletai, kai eis ho khrezon), como dice Eurípides. Pero esto es malo, pues no debe ser considerado una esclavitud el vivir de acuerdo con el régimen, sino una salvación" ${ }^{21}$; retomando así, pero a su manera, lo que indicaba Platón cuando asociaba las leyes que los demócratas no respetan con una especie de amo y, por ende, con una forma de esclavitud que el pueblo rechaza.

En efecto, los pobres, por ser más numerosos, son más poderosos (kyrioterous) que los ricos haciendo que la opinión de la mayoría sea soberana; a esto se suma que la libertad democrática implica el hecho de vivir como cualquiera lo desee (to zên hos bouletai tis); de lo cual se deriva que en este tipo de democracia el pueblo aspira a no ser gobernado por nadie (to me arkhesthai... hypo methenos), poniendo en evidencia así su carácter anárquico; para que cualquiera pueda hacer lo desee tiene que existir una capacidad de decidir no limitada por nada ni por nadie (Política, 1317a 40-b 17). El hecho de tolerar que cualquiera pueda vivir como lo desee (to zên hopos tis bouletai) asimila a los ciudadanos con la anarquía de esclavos, mujeres y niños, subvirtiendo las jerarquías, tal como ya lo denunciaba Platón. Aristóteles concluye: “Gran interés habrá en apoyar esta clase de régimen, pues para la multitud (toîs polloîs) es más placentero (hedion) vivir desordenadamente (te zên ataktos) que con moderación" (1319b 1-32) 22 .

Así, el hecho de que cualquiera haga lo que desee tiene sentido estrictamente en función de caracterizar a la democracia y no al individuo democrático. Cada uno hace lo que quiere porque la libertad y la igualdad se conciben como soberanía de la multitud, cuya expresión política es la soberanía del pueblo decidiendo decretos en

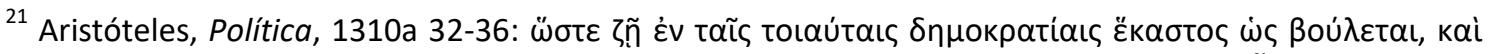

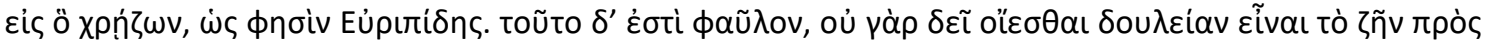
tìv $\pi$ (1988).

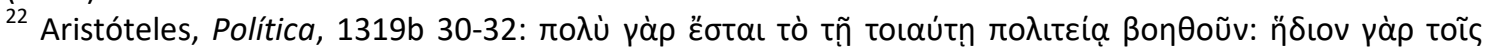

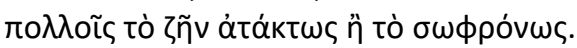


Atenas, entre el amor y la anarquía: la democratización de los placeres y las contingencias de la política popular

asamblea o dictámenes en tribunales ${ }^{23}$. Aristóteles deja ver que en la democracia la posibilidad de que cualquiera pueda hacer lo que se le ocurra significa que la exousia no se deriva de una facultad individual sino de la capacidad colectiva del pueblo para mantener la igualdad aritmética; sin esta última no existiría dicha libertad extrema, que implica prácticamente un abuso de poder. Según indica Fred Miller (1996, pp. $900-$ 901): "Siguiendo a Platón, Aristóteles critica la democracia por identificar la eleutheria con la exousia irrestricta, la capacidad de hacer cualquier cosa que se quiera, que hace que la libertad degenere en licencia, y la pólis en una condición anárquica”.

\section{Los innecesarios placeres democráticos: demerastia y demegoria}

Para Platón y Aristóteles, el mal de la democracia está en su índole placentera (hedeîa, hedion), en el hecho de poder vivir en desorden. Si la moderación primara, los placeres quedarían restringidos, o incluso anulados. Así, el placer irrestricto caracteriza a la política democrática, que habilita la materialización sin límite alguno del deseo de cualquiera. Dimensión evidente de todo esto es la relación amorosa, sexual, símbolo paradigmático de la intersección entre placeres y deseos, salvo que se los controle o se los suprima. Volvamos, una vez más, a Platón, quien ya ha venido preparando desde siempre el golpe de efecto capaz de vincular el carácter placentero de la democracia con la cópula sexual bajo las especies del poder hacer lo que cualquiera desee.

Para Platón, la igualdad y la libertad imperantes en la democracia generan no solo la equiparación entre iguales y desiguales sino que también acarrean una absoluta mezcolanza (pantodapos) y abigarramiento (poikilia). Se podría decir que se trata de un amasijo de hombres de todo tipo, de un seductor manto multicolor con todos los caracteres (República, 557c, 561e), que se asemeja a un enjambre de zánganos, que son calificados como bestias feroces y terribles (aithosi thersi kai deinoîs), lo cual nos devuelve al problema de la disolución de las jerarquías y a la animalidad; al igual que los zánganos, los hombres están colmados y gobernados por múltiples e innecesarios placeres y deseos (hedonôn kai epithymiôn), de toda especie y variedad, entre los que destacan los excesos en la comida y el sexo (aphrodision) (559a-d), dando a entender

\footnotetext{
${ }^{23}$ Cf. Aristóteles, Política, 1292a 2-37; [Aristóteles], Constitución de los atenienses, 41.1-2.
} 
de esta manera que esta situación implica dar rienda suelta a todos los instintos "más bajos", buscando siempre más, y por eso existe el abuso de poder hacer siempre lo que se desee. En estas condiciones, la vida del varón isonómico se asimila al alma del joven con el que Platón ejemplifica el comportamiento del individuo democrático, en el que conviven deseos contradictorios que se multiplican y se fortalecen, llevándolo "hacia las mismas compañías, y en secreta cópula sexual engendran una multitud" 24. En efecto, esta multitud procede de la indiscriminación entre los placeres necesarios y los innecesarios, pues todos se consideran semejantes, sin distinguir los deseos nobles y buenos de los perversos -al igual que sucede con los hombres en la democracia, ya que impone la misma igualdad para iguales y desiguales-, satisfaciendo así cada nuevo deseo que sobreviene (560a-562a): "No hay ningún orden ni obligación en su vida, sino que, considerando esta vida placentera, libre y dichosa (hedyn te de kai eleutherion kai makarion), la lleva a fondo" 25 . Y si de placeres, deseos y cópulas sexuales se trata, la multiplicación y la indiscriminación implican la búsqueda permanente de un plus de goce, de todo tipo y para todos, siempre yendo por más. Una "banda inconsolable", para la que cualquier forma de estimulación resulta siempre algo insuficiente.

En estos pasajes de República no se nomina bajo el signo de eros la urdimbre que se entreteje entre placeres, deseos y coitos. Sin embargo, desde el momento en que la democracia es definida en relación con los placeres y los deseos irrestrictos, sin constricciones ni discriminaciones entre los virtuosos y los perversos, y que éstos se entrecruzan con el acto sexual real o metafórico, entramos en una erótica de la política democrática, como la indagada por Wohl y Scholtz. En este sentido, el libro VIII de República parece elaborar en el plano general del goce lascivo inherente al régimen democrático, y al individuo isonómico que allí se configura, lo que Platón encuadra en un plano más específico en otros diálogos, como en el primer Alcibíades, si se acepta la autenticidad de su autoría, y en Gorgias. Nos referimos a la caracterización que allí se hace de la relación entre el líder y el pueblo bajo el modo de un vínculo amoroso:

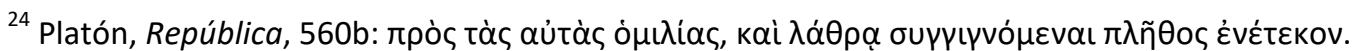

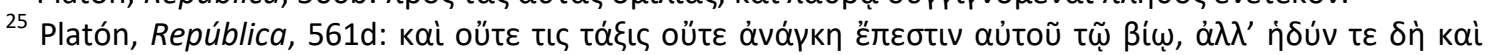

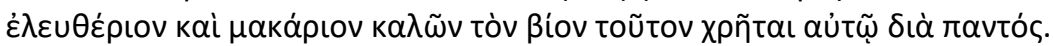


Atenas, entre el amor y la anarquía: la democratización de los placeres y las contingencias de la política popular

¡Esta tolerancia y despreocupación por nuestros requisitos que existe en ella, este desdén hacia los principios que pronunciamos solemnemente cuando fundamos la ciudad, como el de que, salvo que cuente con una naturaleza excepcional, jamás va a llegar a ser un hombre bueno (anêr agathos) si desde la tierna infancia no ha jugado con cosas valiosas ni se ha ocupado con todo lo de esa índole; la soberbia con que se pisotean todos esos principios, sin que nadie se preocupe por cuáles hábitos alguien se encamina hacia la política, sino rindiendo honores con solo que diga que está bien dispuesto hacia la multitud (eunous eînai tôi plethei)! (República, 558b-c) ${ }^{26}$.

Solo en esta ocasión se hace mención, en los pasajes examinados de República, a esta relación en la que se contrapone al hombre bueno (anêr agathos), varón noble educado para guiar la ciudad conforme a los principios de Calípolis, con aquel que recibe honores por el solo hecho de decir: eunous eînai tôi plethei. Esta expresión se puede traducir como: "que es benévolo o benevolente con la multitud", con el sentido que originariamente tienen en latín los adjetivos benevolus y benevolens, es decir, "bien intencionado", o "bien dispuesto". El término eunous registra un uso bastante extendido durante los siglos V y IV, aunque a veces el objeto de dicha benevolencia aparece de modo diferente, en la medida en que se dirige a la ciudad o el pueblo ${ }^{27}$. De las versiones revisadas, sin pretensión de exhaustividad, la francesa de Robert Baccou (1936) y la inglesa de Allan Bloom (1968) traducen eunous como bienveillance y well

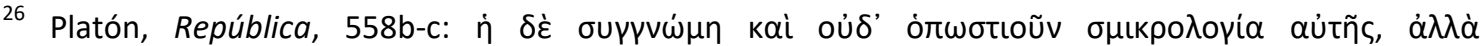

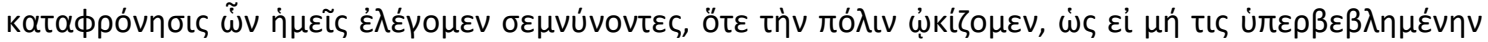

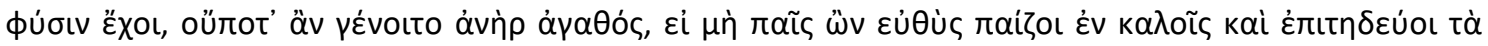

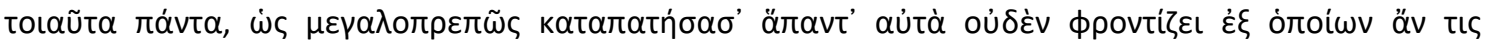

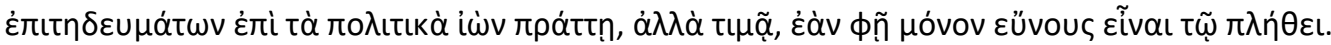

27 Sófocles, Antígona, 209: "benefactor" (eúnous têide têi pólei) (A. Alamillo); [Andócides], 4.16: "favorable" (eunous tôi dêmōi) (J. Redondo Sánchez); Lisias, 14.10: "leal" (eunous tôi pléthei); 18.6: "leal" (eunous tôi hymeterōi plethei); 18.11: "simpatía" (eunous tôi dêmōi); 20.2: "partidario" (eunous tôi plethei tôi hymeterōi); 20.27: "bueno" (eunous têi polei) (J.L. Calvo Martínez); Isócrates, 12.241: "benévolo" (eunous tôi plethei) (J.M. Guzmán Hermida); Demóstenes, 18.84: "amable" (eunous tôi dêmōi); 18.171: "bien dispuesto" (eunous têi polei) (A. López Eire); Exordio, 50.2: "benévolo" (eunous têi polei); Anaxímenes, Retórica a Alejandro, 29.7: “lo mejor" (eunous têi polei) (J.L. López Cruces, Javier Campos Daroca y M.A. Márquez Guerrero). (Las traducciones al español del término eunous consignadas entre comillas proceden de las versiones de las obras citadas publicadas por la Biblioteca Clásica Gredos; se indica entre paréntesis los nombres de quienes han estado a cargo de tales traducciones).
} 
disposed, respectivamente; tres traducciones al español, entre ellas la recién citada de Eggers Lan, vierten “amigo del pueblo" ${ }^{28}$, al igual que en francés Émile Chambry (1934: ami du peuple) y en inglés G.R.F. Ferrari y Tom Griffith (2000: friend of the people); mientras que Paul Shorey (1935) e Ivor A. Richards (1942) proponen sin ambages: he loves the people, "que ama al pueblo", aun cuando Platón use plêthos y no dêmos.

Estos dos últimos casos pueden resultar sobreinterpretaciones, pero ponen de relieve con claridad el problema de la traducibilidad al que aludíamos inicialmente ${ }^{29}$, que en este caso parecen derivarse de un enunciado sobre el que Platón opera en Alcibíades y en Gorgias y que, como ya vimos, es posible rastrear en Tucídides y, sobre todo, en Aristófanes ${ }^{30}$. En este contexto, la expresión con la que Platón caracteriza en República la relación entre la multitud y quien recibe sus honores con solo decir que le es favorable cobra el sentido de amor al pueblo, así como en Caballeros de Aristófanes (779), pues Morcillero le dice a Demo que Paflagonio no lo quiere ni es benévolo con él (oukhi phileî s' oud' est' eunous), siendo el primero quien aparece como noble y amigo del pueblo (gennaîon kai philodemon) (787). En Alcibíades, uno de los ejes del diálogo radica en el modo de persuadir ante el pueblo en la asamblea (114b-d); pero, más allá del objetivo específico de la mayéutica socrática, lo que se pone de relieve es el poder que adquiere el orador que es capaz de convertirse en líder (105a-b), aunque también la potencia del pueblo, que en términos platónicos se plantea como una corrupción de quienes se dejan llevar por el amor del pueblo, tal como Sócrates le dice a Alcibíades:

Y ahora, si no te corrompe (diaphtharêis) el pueblo ateniense y no te vuelves peor, no te abandonaré. Pues esto es lo yo más temo: que convirtiéndote en amante del pueblo (demerastes) te nos corrompas (diaphtharêis), puesto que a muchos buenos (agathoi) atenienses les ha pasado eso anteriormente $(132 a)^{31}$.

\footnotetext{
${ }^{28}$ Cf. Camarero (1963); Gómez Robledo (1971). (Cabe reiterar que alteramos la versión de Eggers Lan).

${ }^{29}$ Solo como un indicio, ver las distintas versiones españolas para el término eunous citadas en n. 27.

${ }^{30}$ Cf. Nightingale (1995, pp. 185-190); Petre (2009, pp. 160-163).

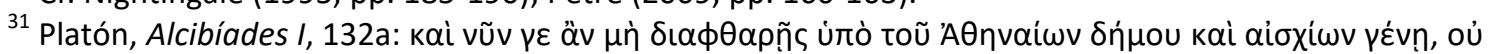

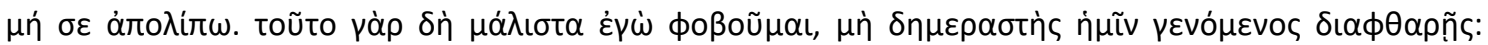

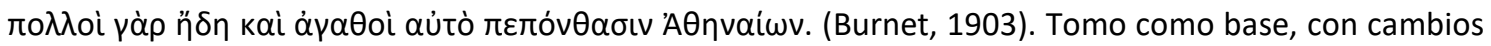
significativos, la traducción al español de Velásquez (2013).
} 
Atenas, entre el amor y la anarquía: la democratización de los placeres y las contingencias de la política popular

Como se deduce de los argumentos de Victoria Wohl (1999; 2002, pp. 124-170), esta formulación solo destaca los efectos del rol del pueblo sobre Alcibíades, a quien Sócrates pretende rescatar, puesto que hay otra imagen del líder que se construye a partir de su papel como tirano respecto del cual los atenienses serían sus eromenoi. Pero prosigamos en el terreno de los diálogos platónicos y saquemos ciertos corolarios de las interferencias que parecen surgir entre la demerastia de los demagogos cómicos y de Alcibíades y la eunoia de los líderes cuando esta se dirige a la muchedumbre. En efecto, el término demerastês parece conectarse con el enunciado eunous tôi plethei, y, de forma implícita, haber guiado su lectura con el sentido de amigo o amante del pueblo, dado el contexto en el que esta expresión se insiere en el ya comentado pasaje de República, donde el accionar del líder que solo busca la aprobación de la multitud depende de un régimen político que con total arrogancia degrada, desprecia y pisotea las excelsas pautas de Calípolis. En cualquier caso, el punto principal es que la relación entre el pueblo y los líderes se representa como un vínculo amoroso en el que éstos tienen la función activa con respecto a aquél y donde no se puede excluir las evidentes connotaciones sexuales, evocando el papel del adulto en relación con el joven en la pederastia griega, que es fundamentalmente un acoplamiento homoerótico concebido como paideia en el marco de los círculos aristocráticos, como las heterías áticas ${ }^{32}$. En la comedia de Aristófanes, como vimos, Morcillero se encarga de poner en claro que el problema no radica en concebir de esta manera la relación entre el pueblo y los líderes sino en que aquél no elige a los kaloi k'agathoi para que desempeñen como dirigentes. Si esto último ocurriera, conforme a los intereses de los caballeros, entonces el pueblo en posición de eromenos sería bien dirigido y educado adecuadamente por sus erastai.

Pero para Platón la cuestión no es tan sencilla, porque el problema no radica en el estatus de quienes ejercen el liderazgo sino en la existencia misma de la democracia, aun si en Gorgias la corrupción que el pueblo produce en quien pretende liderarlo se presenta como una que, a la inversa de Alcibíades, afecta a los ciudadanos a partir de

${ }^{32}$ Cf. Dover (1989, pp. 164-165, 2002). 
la adulación del demagogo ${ }^{33}$. En este sentido, uno de los ejes centrales del diálogo gira en torno al papel de la retórica y, por consiguiente, del orador, insistiendo en torno de la demegoria y el demegoros, es decir, la oratoria de asamblea y quien la practica. Precisamente, la definición socrática de la retórica como un simulacro (eidolon) de una parte de la política se debería al hecho de que aquélla funciona a partir de la adulación (kolakeia) con el fin de procurar regocijo y placer (kharitos kai hedonês) momentáneos, pero, al mismo tiempo, engañando (exapatâi) a quienes escuchan los discursos como si fueran entendidos, pero que en rigor caen en la insensatez (462d-465e). No obstante, el vínculo entre orador y audiencia no se establece de forma unidireccional, puesto que aquél cambia su parecer conforme a las demandas de ésta. Esto es lo que se pone de relieve al final del diálogo en la comparación que Sócrates establece entre sus dos amores (erônte), Alcibíades y la filosofía, y los dos de Calicles, el dêmos ateniense y Demo el hijo de Pirilampes. En virtud de la analogía entre las posiciones de Sócrates y Calicles, ambos aparecen en la posición activa del adulto que ya indicamos en relación con el uso de la palabra demerastês en Alcibíades. Pero Calicles siempre cede ante los cambios de humor de sus amados, quienes aparecen evocados dos veces mediante ta paidika y tôn paidikôn en clara referencia a la metafórica situación etaria de ambos:

Me doy cuenta de que, en ninguna ocasión, aunque eres hábil, puedes oponerte a lo que dicen tus amores (ta paidika), ni a sus puntos de vista, sino que te dejas llevar por ellos de un lado para otro. En la asamblea, si expresas tu parecer y el pueblo ateniense dice que no es así, cambias de opinión y dices lo que él desee (bouletai); también respecto a ese bello joven (neanian), el hijo de Pirilampes, te sucede otro tanto. En efecto, no eres capaz de hacer frente a las determinaciones ni a las palabras de tus amores (tôn paidikôn) $(481 d-e)^{34}$.

\footnotetext{
${ }^{33}$ Ver Newel (2000, pp. 9-41). Cf. Paizi (2014).

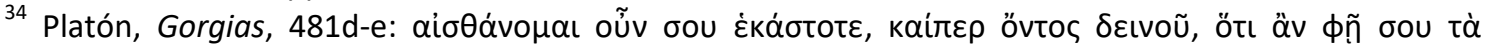

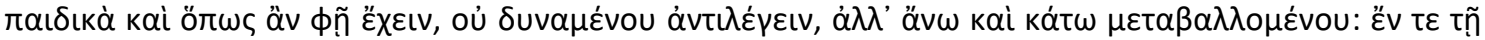

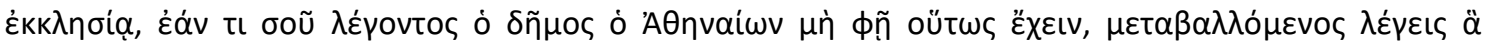

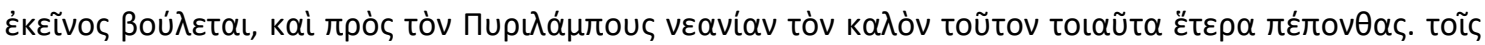

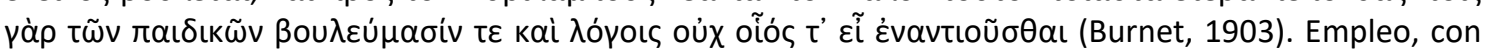
leves cambios, la traducción al español de Calonge Ruiz, en idem, Acosta, Olivieri \& Calvo (1983).
} 
Atenas, entre el amor y la anarquía: la democratización de los placeres y las contingencias de la política popular

Así pues, el orador amante termina siendo arrastrado a hacer todo lo que el pueblo amado desee, en la medida en que esto sería lo constitutivo de la democracia. Nuevamente, al igual que en Alcibíades, el poder del líder solo es posible en virtud de la potencia del pueblo ateniense, que admite como líder a quien sea el más semejante a él (homoiotaton) y que actúe como su amigo (prosphilês). Calicles solo conseguirá la amistad (philía) del dêmos ateniense y de Demo el hijo de Pirilampes volviéndose el más semejante a uno y otro: así, el líder se convierte en político y orador, y aquéllos se regocijan (khairousi) porque escuchan lo que concuerda con su pensamiento.

La democracia en sus prácticas concretas, en su funcionamiento asambleario, está, pues, atravesada por el goce: placer, deseo, amor, sexo, regocijo; a punto tal que, ante una nueva disquisición de Sócrates que Calicles no acaba de comprender (513a-c), aquél concluye su diagnóstico de la siguiente manera: "El amor del pueblo (ho dêmou... eros), sin duda, Calicles, arraigado en tu alma me hace frente" ${ }^{35}$. Esta articulación entre dêmos y eros, en el marco de los vínculos pederastas aludidos en el diálogo, repone la forma amorosa graficada por demerastês en Alcibíades: "El amor del pueblo, concluye Rachana Kamtekar (2005, p. 338), manifestado en la forma en que el pueblo guía sus deseos y aversiones, ha resultado ser el más básico de los compromisos de Calicles".

\section{A modo de conclusión}

¿Qué es lo que tanto molesta de estas relaciones entre los líderes y pueblo y, por consiguiente, del régimen democrático? ¿A qué responden estas representaciones pornográficas denigrantes de dichos vínculos entre líderes y pueblo en la asamblea? La democratización del goce, esto es, la capacidad del pueblo para plasmar una relación amorosa en la que establece las condiciones del vínculo y su permanencia, tiene como factor básico la igualdad sin atenuantes, irrestricta, tanto de los integrantes del pueblo como de quienes se convierten en sus líderes. Entre aquéllos se cuentan todos los que la élite aristocrática consideraba viles, inferiores, los poneroi, elevados al mismo rango sociopolítico que los que se autopercibían como "naturalmente" honestos, superiores, los khrestoi, dicotomía bien graficada en el libelo República de los atenienses del Viejo

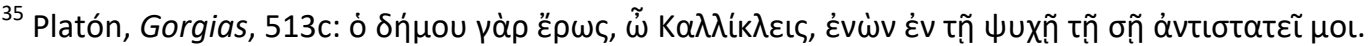


Oligarca. No olvidemos, en este marco, que partiendo de la equiparación entre padres e hijos Platón llegaba a la de hombres y animales como acción y efecto de la existencia misma de la democracia. Como se pone de relieve en otro pasaje de República (557a): "Entonces, la democracia surge, pienso, cuando los pobres, tras lograr la victoria (hoi penetes nikesantes), matan a unos, destierran a otros, y a los demás (toîs loipoîs) los hacen partícipes en igualdad (ex isou metadôsi) del gobierno y las magistraturas" ${ }^{\prime 36}$.

Es ese resto, como sentido específico de loipos, sin más autoridad que la fuerza de su victoria sobre la parte "naturalmente" autorizada para gobernar, lo que está en el origen de la democracia desde su instauración. Pero esta mescolanza promiscua es también la de los líderes: el pueblo no es amante de los kaloi k'agathoi sino de los vendedores de lámparas, cordeleros, zapateros o curtidores; y cuando se trata de un líder de origen aristocrático, el problema es que el pueblo termina corrompiéndolo, y, finalmente, se convierte en alguien igual al pueblo, a quien debe parecerse para poder liderarlo. Así, al entrar en ese vínculo amoroso, todos se vuelven parte de ese resto no calificado: esa relación de placer y deseo instituye el propio destino de la democracia.

En efecto, del Discurso Fúnebre que Tucídides atribuye a Pericles -en el que los atenienses aparecen como amantes (erastas) de una entidad abstracta como la pólis sin que haya allí placer alguno-, a los pasajes de Caballeros de Aristófanes -en los que se repone el principio del placer-deseo como inherente a las relaciones amorosas ya no con la ciudad sino entre los demagogos y el pueblo atenienses, a partir de la figura del erastês toû demou, apelando a los roles activo y pasivo de las relaciones pederastas y transformando la metafórica relación amorosa en prostitución-, vemos esbozarse un discurso eminentemente crítico de la situación democrática, que lecturas posteriores como las de Isócrates, Platón y Aristóteles no cesarán de profundizar, en primer lugar, poniendo de relieve los excesos característicos de la democracia que se condensan en la exousia y la anarquía, no como derivas de un funcionamiento que se deja de ajustar a la norma sino como aspectos que le son inherentes. En segundo lugar, es sobre todo esto que Platón se monta en Gorgias, donde la demegoria es la otra cara del "amor del pueblo" que ponen de manifiesto los demagogos en sus actitudes como una condición

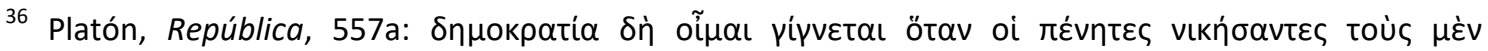

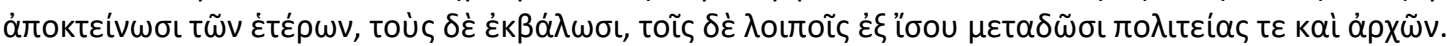


Atenas, entre el amor y la anarquía: la democratización de los placeres y las contingencias de la política popular

que estos tienen interiorizada, ya arraigada en su alma, y en Alcibíades I, donde acuña el término demerastês para señalar, al igual que Aristófanes, la relación promiscua del líder con el pueblo, en la medida en que aquel es corrompido por este, según Platón, pero donde, paradójicamente, el primero aparece con el rol activo del erastês y el segundo el rol pasivo del eromenos, invirtiendo los lugares del corruptor y el corrupto.

Concluyendo nuestro recorrido, podemos afirmar que todas estas expresiones críticas buscan des-investir al dêmos de su singular poder por su falta de cualificación, su mescolanza, su desorden, incapacitado como estaría de practicar el verdadero amor con los andres agathoi. Por ende, como cualquiera disfruta del placer de hacer lo que desee y tiene la opción de elegir entre un sinnúmero abigarrado de comportamientos heterogéneos, la democracia resulta ser entonces un régimen político anárquico. Esta carencia de autoridad superior, que es a un tiempo una falta de medida, hace posible que se aplique el mismo criterio de igualdad sin distinguir entre quienes lo merecerían y aquellos que no lo merecerían. Esta indiscriminación es ese resto, ese equívoco, que radica en el dêmos considerado al mismo tiempo como el conjunto y como una parte del mismo; pues, sin diferenciación, sin principio de autoridad, en definitiva, sin arkhe, predomina en la situación democrática la anarquía de la igualación de cualquiera con cualquiera37. Retomando a Jacques Rancière (1996, p. 30), el mal de la democracia no radica en el deseo insaciable de más goces y placeres de "esa banda inconsolable": "El mal no es el siempre más sino el cualquiera, la revelación brutal de la anarquía última sobre la que descansa toda jerarquía". El mal, pues, no radica en el goce en sí sino en que la democracia lo pone a disposición de cualquiera, de esa banda hecha de restos. ¿Dijimos democracia? Remplacemos por "populismo" y tendremos el discurso actual en que predomina la denigración del pueblo cuando aparece como sujeto político.

\section{Referencias bibliográficas}

Agamben, G. (2000). Lo que queda de Auschwitz: El archivo y el testigo. Homo sacer III [1998]. (A. Gimeno Cuspinera, trad.). Valencia: Pre-Textos.

Baccou, R. (1936). Platon. Oeuvres complètes, IV: La République (intr., trad. y notas).

\footnotetext{
${ }^{37}$ Remito aquí a los desarrollos de mi libro: Gallego (2018).
} 
Paris: Garnier.

Balot, R.K. (2001). Pericles' Anatomy of Democratic Courage. American Journal of Philology, 122, 505-525.

Balot, R.K. (2004a). Courage in the Democratic Polis. Classical Quarterly, 54, 406-423.

Balot, R.K. (2004b). Free Speech, Courage, and Democratic Deliberation. En I. Sluiter \& R. Rosen (eds.), Free Speech in Classical Antiquity (pp. 233-259). Leiden: Brill.

Balot, R.K. (2004c). The Dark Side of the Democratic Courage. Social Research, 71, 73106.

Balot, R.K. (2007). Subordinating Courage to Justice: Statecraft and Soulcraft in FourthCentury Athenian Rhetoric and Platonic Political Philosophy. Rhetorica, 25, 35-52.

Balot, R.K. (2008). Socratic Courage and Athenian Democracy. Ancient Philosophy, 28, 49-69.

Balot, R.K. (2009). The Virtue Politics of Democratic Athens. En S.G. Salkever (ed.), The Cambridge Companion to Ancient Greek Political Thought (pp. 271-300). Cambridge: Cambridge University Press.

Balot, R.K. (2010). Democratizing Courage in Classical Athens. En D.M. Pritchard (ed.), War, Democracy and Culture in Classical Athens (pp. 88-108). Cambridge: Cambridge University Press.

Balot, R.K. (2014). Courage in the Democratic Polis: Ideology and Critique in Classical Athens. Oxford: Oxford University Press.

Bloom, A. (1968). The Republic of Plato (intr., trad. y notas). New York: Basic.

Breaugh, M. (2007). L'expérience plébéienne: Une histoire discontinue de la liberté politique, Paris: Payot.

Brémond, É. \& Mathieu, G. (1962). Isocrate. Discours, IV: Philippe-PanathénaïqueLettres-Fragments (ed., intr., trad. y notas). Paris: Les Belles Lettres.

Burnet, J. (1902-7). Platonis opera. Oxford: Oxford Classical Texts.

Calame, C. (2002). Eros en la Antigua Grecia [1992]. (E. Pérez Rodríguez, trad.). Madrid: Akal.

Calhoun, C. \& Solomon, R. (eds. 1984). What is an Emotion? Classic Readings in Philosophical Psychology. Oxford: Oxford University Press. 
Atenas, entre el amor y la anarquía: la democratización de los placeres y las contingencias de la política popular

Calonge Ruiz, J., Acosta, E., Olivieri, F.J. \& Calvo, J.L. (1983). Platón. Diálogos, II: Gorgias-Menéxeno-Eutidemo-Menón-Crátilo (intr., trad. y notas). Madrid: Gredos.

Camarero, A. (1963). Platón. República (trad.; intr. y notas L. Farré). Buenos Aires: EUDEBA.

Cassin, B. (2016). Éloge de la traduction: Compliquer l'universel. Paris: Fayard.

Chambry, É. (1934). Platon. Oeuvres complètes, VII/2 ${ }^{e}$ : La République, Livres VIII-X (ed., intr. y trad.). Paris: Les Belles Lettres.

Coulon, V. \& van Daele, M. (1923). Aristophane, I: Les Acharniens-Les Cavaliers-Les Nuées (ed., intr., trad. y notas). Paris: Les Belles Lettres.

Dover, K.J. (1989). Greek Homosexuality ${ }^{2}$ [1978]. Cambridge MA: Harvard University Press.

Eggers Lan, C. (1986). Platón. Diálogos, 4: República (intr., trad. y notas). Madrid: Gredos.

Ferrari, G.R.F. \& Griffith, T. (2000). Plato. The Republic (ed., intr. y trad.). Cambridge: Cambridge University Press.

Gallego, J. (2011). Degeneraciones y regeneraciones de un cuerpo (político). Las somatizaciones de la ciudadanía en la democracia ateniense. En M. Calafell \& A. Pérez (eds.), El cuerpo en mente: Versiones del ser desde el pensamiento contemporáneo (pp. 337-344). Barcelona: Universitat Oberta de Catalunya.

Gallego, J. (2014). Si esto es un hombre (griego): la subjetividad del ciudadano modélico y los seres desubjetivados. Phoînix, 20/1, 40-58.

Gallego, J. (2015). La desubjetivación del dêmos: pérdida del coraje político y olvido del acontecimiento democrático. Phoînix, 21/2, 59-84.

Gallego, J. (2016). La asamblea, el teatro y el pensamiento de la decisión en la democracia ateniense. Nova Tellvs, 33/2, 13-54

Gallego, J. (2018). La anarquía de la democracia: Asamblea ateniense y subjetivación del pueblo. Buenos Aires: Miño y Dávila.

Gallego, J. \& Fernández, C.N. (eds. 2019). Democracia, pasón de multitudes: Política, comedia y emociones en la Atenas clásica. Buenos Aires: Miño y Dávila.

García Valdés, M. (1988). Aristóteles. Política (intr. trad. y notas). Madrid: Gredos. 
Gil Fernández, L. (1995). Aristófanes. Comedias, I: Los Acarnienses-Los Caballeros (intr., trad. y notas). Madrid: Gredos.

Gómez Robledo, A. (1971) Platón. La República (bilingüe; intr., trad. y notas). México: Universidad Nacional Autónoma de México.

Guzmán Guerra, A. (1989). Tucídides. Historia de la Guerra del Peloponeso (intr., trad. y notas). Madrid: Alianza.

Guzmán Hermida, J.M. (1980). Isócrates. Discursos, // (intr., trad. y notas). Madrid: Gredos.

Jones, H.S. \& Powell, J.E. (1942). Thucydidis historiae, I: Books I-IV (ed.). Oxford: Oxford Classical Texts.

Kamtekar, R. (2005). The Profession of Friendship: Callicles, Democratic Politics, and Rhetorical Education in Plato's Gorgias. Ancient Philosophy, 25/2, 319-339.

Konstan, D. (2004). Las emociones en la antigüedad griega. Pensamiento y Cultura, 7, 47-54.

Konstan, D. (2006). The Emotions of the Ancient Greeks: Studies in Aristotle and Classical Literature. Toronto: University of Toronto Press.

Konstan, D. (2007). Anger, Hatred, and Genocide in Ancient Greece. Common Knowledge, 13/1, 170-186.

Konstan, D. \& Rutter, K. (eds. 2003). Envy, Spite and Jealousy: The Rivalrous Emotions in Ancient Greece, Edinburgh: Edinburgh University Press.

Koziak, B. (2000). Retrieving Political Emotion: Thumos, Aristotle, and Gender, Pennsylvania: Pennsylvania State University Press.

Loraux, N. (2008a). La ciudad dividida: El olvido en la memoria de Atenas [1997]. (S. Vassallo, trad.). Buenos Aires: Katz.

Loraux, N. (2008b). La guerra civil en Atenas: La política entre la sombra y la utopía [2005]. (A. Iriarte, trad.). Madrid: Akal.

Lozano Nembrot, M. (2016). Amores en pugna: desarrollos y tensiones de la concepción de éros en Esquines y Platón. Controvérsia, 12/1, 30-36.

Lozano Nembrot, M. (2018a). La erótica griega y el problema de la enkráteia. En M.C. Colombani, G. Fernández Parmo \& J.M. Gerardi (eds.), Actas del Tercer Simposio 
Atenas, entre el amor y la anarquía: la democratización de los placeres y las contingencias de la política popular

Nacional de Filosofía Antigua: "Legalidad cósmica y legalidad humana en la Filosofía Antigua" (pp. 191-201). Mar del Plata: Universidad Nacional de Mar del Plata (http:// www.aafa.org.ar/AAFA-Actas III Simposio Nacional de Filosofia Antigua.pdf).

Lozano Nembrot, M. (2018b). Los erotikoì lógoi de Lisias y la moral griega. Symploké: Revista Filosófica, 8, 51-67.

Ludwig, P. (2002). Eros and Polis: Desire and Community in Greek Political Theory. Cambridge: Cambridge University Press.

Mathieu, G. (1942). Isocrate. Discours, III: Sur la paix-Aréopagitique-Sur l'échange (ed., intr., trad. y notas). Paris: Les Belles Lettres.

Miller, F. (1996). Aristotle and the Origins of Natural Rights. Review of Metaphysics, 49, 873-907.

Monoson, S.S. (1994). Citizen as Erastes: Erotic Imagery and the Idea of Reciprocity in the Periclean Funeral Oration. Political Theory, 22/2, 253-276.

Montepaone, C. (1992). Bendis tracia ad Atene: I'integrazione del 'nuovo' attraverso forme dell'ideologia. En M.-M. Mactoux \& É. Geny (eds.), Mélanges Pierre Lévêque, 6: Religion (pp. 201-219). Paris: Les Belles Lettres.

Newel, W. (2000). Ruling Passions: The Erotics of Statecraft in Platonic Political Philosophy. Lanham: Rowman \& Littlefield.

Nightingale, A.W. (1995). Genres in Dialogue: Plato and the Construct of Philosophy. Cambridge: Cambridge University Press.

Nussbaum, M. (2001). Upheavals of Thought: The Intelligence of Emotions. Cambridge: Cambridge University Press.

Nussbaum, M. (2004). Hiding from Humanity: Disgust, Shame, and the Law. Princeton: Princeton University Press.

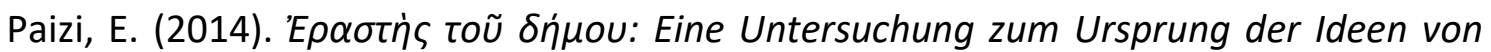
Kallikles in Platons "Gorgias", Heidelberg (Trabajo de Seminario: "Platons politische Philosophie und die zeitgenössische Politik", Prof. Dr. Kai Trampedach). (DOI: 10. 13140/rg.2.2.32235.85288; consulta: 07/09/2018).

Petre, Z. (2009). Revenants et sauveurs: le Ménexène de Platon et le théâtre attique. En M. Neamţu \& B. Tătaru-Cazaban (eds.), Memory, Humanity, and Meaning: Selected 
Essays in Honor of Andrei Pleşu's Sixtieth Anniversary (pp. 155-168). Bucharest: Zeta.

Rancière, J. (1996). El desacuerdo: Política y filosofía [1995]. (Horacio Pons, trad.). Buenos Aires: Nueva Visión.

Richards, I.A. (1942). The Republic of Plato (intr. y trad.). New York: Norton.

Robson, J. (2013). The Language(s) of Love in Aristophanes. En E. Sanders, C. Thumiger, C. Carey \& N.J. Lowe (eds.), Erôs in Ancient Greece (pp. 251-266). Oxford: Oxford University Press.

Ross, W.D. (1957). Aristotelis política (ed.). Oxford: Oxford Classical Texts.

Rothwell Jr., K.S. (1990). Politics and Persuasion in Aristophanes' Ecclesiazusae. Leiden: Brill.

Santoro, D. (2014). El peronismo es la democratización del goce. Nac\&Pop: Red Nacional y Popular de Noticias, 28 de septiembre (http://nacionalypopular.com/2014/ 12/20/el-peronismo-es-la-democratizacion-del-goce/\#23; consulta: 12/10/2018).

Scholtz, A. (2004). Friends, Lovers, Flatterers: Demophilic Courtship in Aristophanes' Knights. Transactions of the American Philological Association, 134, 263-293.

Scholtz, A. (2007). Concordia Discors: Eros and Dialogue in Classical Athenian Literature. Washington DC: Center for Hellenic Studies.

Shorey, P. (1935). Plato. The Republic, II: Books VI-X (ed., intr. y trad.). Cambridge MA: Harvard University Press.

Solana Dueso, J. (1994). Aspasia de Mileto: Testimonios y discursos. Barcelona: Anthropos.

Torres Esbarranch, J.J. (1990). Tucídides. Historia de la Guerra del Peloponeso: Libros III (trad. y notas; intr. J. Calonge Ruiz). Madrid: Gredos.

Velásquez, Ó. (2013). Alcibíades (intr., ed., trad. y com.). Santiago de Chile: Tácitas. Wertmüller, L. (1973). Film d'amore e d'anarchia, ovvero: Stamattima alle 10 in via dei Fiori nella nota casa di tolleranza (http://www.linawertmuller.com/schede/film.htm; consulta: $12 / 10 / 2018)$.

Wohl, V. (1999). The Eros of Alcibiades. Classical Antiquity, 18/2, 349-385.

Wohl, V. (2002). Love among the Ruins: The Erotics of Democracy in Classical Athens. Princeton: Princeton University Press. 